\title{
Cluster randomized trial comparing standard versus enhanced implementation strategies for improving outreach to persons with SMI: 12-month results
}

\author{
David E Goodrich ${ }^{1,2}$, Daniel Almirall ${ }^{3,4}$, Kristin M Abraham, ${ }^{1,5}$, Kristina M Nord ${ }^{1,2}$, Zongshan Lai ${ }^{1,2}$, \\ Nicholas W Bowersox ${ }^{1,2}$, Amy M Kilbourne ${ }^{1,2^{*}}$
}

From 7th Annual Conference on the Science of Dissemination and Implementation in Health North Bethesda, MD, USA. 8-9 December 2014

\section{Objective}

This study compared the effectiveness of an enhanced versus standard implementation strategy (Replicating Effective Programs-REP) for providers at VA outpatient facilities on improving uptake of a national outreach program for Veterans with serious mental illness (Re-Engage) among sites not initially responding to a standard implementation strategy.

\section{Methods}

Initially, Re-Engage was implemented at $158 \mathrm{VA}$ facilities by mental health providers who received the standard REP strategy to support uptake (implementation manual, training, and technical assistance). Re-Engage involved giving providers a list of patients with serious mental illness who had not been seen at their facility for at least a year, requesting that providers contact these patients, assess their clinical status, and where appropriate, expedite VA healthcare appointments. At month 6, facilities considered non-responsive $(\mathrm{N}=88$, total of 3,200 patients), defined as $<80 \%$ of patients on providers' lists with updated assessment of clinical status, were randomized to receive either Enhanced REP (REP+Facilitation; $\mathrm{N}=39$ practices) for 6 months followed by standard REP for 6 months; or continued standard REP ( $\mathrm{N}=49$ practices) for 6 months followed by 6 months of Enhanced REP for facilities still not

\footnotetext{
* Correspondence: amykilbo@umich.edu

'VA Center for Clinical Management Research, VA Ann Arbor Healthcare System, Ann Arbor, MI, 48105, USA

Full list of author information is available at the end of the article
}

responding. Enhanced REP consisted of monthly phonebased coaching by national experts in Re-Engage on overcoming adoption barriers. Quantitative outcomes included attempted contacts and subsequent receipt of outpatient care.

\section{Results}

Patients from facilities randomized to receive Enhanced compared to standard REP were more likely to have an attempted contact $(30 \%$ vs. $13 \%, \mathrm{p}<.001)$. Sites that received Enhanced REP six months after randomization (delayed implementation of Facilitation) were no more likely to have increased contacts. There were no differences in patient-level utilization between Enhanced and standard REP sites 12 months postrandomization.

\section{Implications}

Adaptive implementation intervention strategies like Enhanced REP when applied immediately to address implementation non-response, offer a means to augment implementation efforts.

\section{Funding Source \\ VA HSR\&D (SDR 11-232).}

\begin{abstract}
Authors' details
'VA Center for Clinical Management Research, VA Ann Arbor Healthcare System, Ann Arbor, MI, 48105, USA. ²Department of Psychiatry, University of Michigan Medical School, Ann Arbor, MI, 49109-2800, USA. ${ }^{3}$ Institute for Social Research, University of Michigan, Ann Arbor, MI 48104-2321, USA. ${ }^{4}$ School of Public Health, University of Michigan, Ann Arbor, MI 48109-5425, USA. ${ }^{5}$ University of Detroit Mercy, Detroit, MI 48221-3038, USA.
\end{abstract}


doi:10.1186/1748-5908-10-S1-A26

Cite this article as: Goodrich et al:: Cluster randomized trial comparing standard versus enhanced implementation strategies for improving outreach to persons with SMI: 12-month results. Implementation Science 2015 10(Suppl 1):A26.

Submit your next manuscript to BioMed Central and take full advantage of:

- Convenient online submission

- Thorough peer review

- No space constraints or color figure charges

- Immediate publication on acceptance

- Inclusion in PubMed, CAS, Scopus and Google Scholar

- Research which is freely available for redistribution

Submit your manuscript at www.biomedcentral.com/submit 